\title{
Gambling and sexual behaviors in African-American adolescents
}

\author{
Silvia S. Martins, MD, PhD ${ }^{1}$, Grace P. Lee, MHS, $\mathrm{PhD}^{2}$, June H. Kim, MHS ${ }^{1}$, Elizabeth \\ Letourneau, $\mathrm{PhD}^{2}$, and Carla L. Storr, $\mathbf{M P H}, \mathrm{ScD}^{2,3}$ \\ ${ }^{1}$ Department of Epidemiology, Columbia University \\ ${ }^{2}$ Department of Mental Health, Johns Hopkins Bloomberg School of Public Health \\ ${ }^{3}$ Department of Family and Community Health, University of Maryland School of Nursing
}

\begin{abstract}
Objectives-Late adolescence represents a developmental risk period when many youth become involved in multiple forms of high-risk behaviors with adverse consequences. This study assessed the degree to which two such behaviors, adolescent sexual behaviors and gambling, were associated in a community-based sample with a large African American presence.
\end{abstract}

Study design-Data are derived from a cohort study. This study focuses on 427 AfricanAmerican participants with complete information on gambling and sexual behaviors by age 18 ( $72 \%$ of original cohort). Gambling involvement and related problems were based on responses to the South Oaks Gambling Screen-Revised for Adolescents. Several questions assessed sexual behaviors, including age of initiation. Multivariable logistic regression models adjusted for demographics, intervention status, impulsivity, depressive and anxiety symptoms, and alcohol and illegal drug use.

Results-Almost half of the sample $(49 \%, \mathrm{n}=211)$ had gambled at least once before age 18 . More gamblers than non-gamblers had initiated sexual intercourse by age 18 (aOR: 2.29[1.16, 4.52]). Among those who had initiated sexual activity, more gamblers than non-gamblers with high impulsivity levels at age 13 (vs. low impulsivity levels) had become pregnant or had impregnated someone. Among those who had initiated sexual activity by age 18, more male gamblers had impregnated someone by age 18 as compared to female gamblers becoming pregnant.

Conclusions-Gambling and sexual behaviors often co-occur among adolescents. Such findings prompt the need for the inclusion of gambling, an often overlooked risky behavior, in behavioral prevention/intervention programs targeting adolescents.

(C) 2014 Elsevier Ltd. All rights reserved.

Address correspondence to: Silvia S. Martins, Department of Epidemiology, Mailman School of Public Health, 722 West $168^{\text {th }}$ Street, Rm. 509, New York NY, 10032, [ ssm2183@ columbia.edu], 212-305-2848/410-929-9303.

Publisher's Disclaimer: This is a PDF file of an unedited manuscript that has been accepted for publication. As a service to our customers we are providing this early version of the manuscript. The manuscript will undergo copyediting, typesetting, and review of the resulting proof before it is published in its final citable form. Please note that during the production process errors may be discovered which could affect the content, and all legal disclaimers that apply to the journal pertain. 


\section{Introduction}

Given the recent resurgence of legalized gambling in North America (National Research Council, 1999), considerable attention has been paid to the increased potential for problem and pathological gambling (PG). Late adolescence represents a developmental risk period associated with the onset of gambling problems (Huang, Jacobs, Derevensky, Gupta, \& Paskus, 2007; K. C. Winters, Stinchfield, Botzet, \& Anderson, 2002) as well as with a sequela of other risk behaviors that might have begun earlier, such as sexually transmitted diseases and unwanted pregnancies following the early initiation of sex (Coker et al., 1994; Kotchick, Shaffer, Forehand, \& Miller, 2001; Lee, Storr, Ialongo, \& Martins, 2013; Ompad et al., 2006; Stanton, Li, Cottrell, \& Kaljee, 2001). It has been posited that the co-occurrence of gambling problems and early sexual initiation may be indicative of a common underlying personality characteristic such as impulsivity (Petry, 2000), which has separately been associated with the severity of gambling problems (Lee, Storr, Ialongo, \& Martins, 2011; Liu et al., 2013; Steel \& Blaszczynski, 1998) and early onset of sexual intercourse (Petry, 2000; Stanton et al., 2001).

Several studies have identified the co-occurrence of problem gambling and early onset of sexual intercourse. For example, among $8^{\text {th }}-12^{\text {th }}$ grade students (mainly white) in 79 public and private schools in Vermont $(\mathrm{n}=16,948)$, gambling and problem gambling were associated with earlier age of onset of sexual intercourse (Proimos, DuRant, Pierce, \& Goodman, 1998). Studies of U.S. college students have also shown similar findings regarding gambling and risky sexual behaviors (Zuckerman \& Kuhlman, 2000), including unprotected sex (Huang, Jacobs, \& Derevensky, 2010; Huang et al., 2007). However, as with most studies on adolescent gambling behaviors, the participants in these samples were predominantly white. To our knowledge, only one study examining both adolescent gambling and sexual intercourse included a substantial sample of African Americans (53\% of sample), though study participants were limited to adolescent outpatients in treatment for cannabis abuse $(\mathrm{n}=255$, mean age $=15.9$ years) (Petry \& Tawfik, 2001). Compared to nonproblem gamblers, problem gamblers were more likely to be African American, to have more sex partners, and to have unprotected sex (Petry \& Tawfik, 2001). Despite evidence that problem or pathological gambling is more prevalent among African-American adolescents and adults (Barnes, Welte, Hoffman, \& Tidwell, 2009; Barry, Stefanovics, Desai, \& Potenza, 2011; Welte, Barnes, Wieczorek, Tidwell, \& Parker, 2004), relatively few adolescent studies have included a large subgroup of African Americans in their samples.

The main aim of the present study is to assess the degree to which adolescent sexual behaviors (including early age of onset of sexual activities, unprotected sex, having multiple sex partners) and related unintended consequences (including adolescent pregnancy/ impregnation, sexually transmitted infections [STI]) are associated with gambling behaviors (i.e., any gambling, gambling frequency, any gambling problems) by age 18 in a community sample of African- American inner city youth, controlling for demographics, intervention status, substance use, early adolescent depressive and anxiety symptoms, and impulsivity. We hypothesize that, relative to non-gamblers, gamblers would be more likely to report earlier age of sex initiation, higher number of sex partners, higher prevalence of unprotected sex, and higher prevalence of STIs. We also hypothesize that these associations would be 
stronger for frequent versus infrequent gamblers and for those with gambling problems versus gamblers with no problems.

\section{Methods}

\section{Design and sample}

Data for this study came from participants of a randomized prevention trial who were recruited as they entered first grade. Details of the trial are available elsewhere(N. Ialongo, Poduska, Werthamer, \& Kellam, 2001). In brief, in the Fall of 1993, first grade classrooms from nine urban primary public schools primarily located in western Baltimore, MD were randomly allocated into the control or one of two intervention classrooms. One intervention created opportunities for more positive attention from teachers and peers and the other targeted enhanced parent-school communication, while the control group received the customary curriculum ((N. Ialongo et al., 2001). The intervention lasted for one year, but the cohort of 678 students (entry mean age $=6.2$ years, 53\% male, 88\% African American, $71 \%$ received subsidized lunches, $57 \%$ single parent/caregiver head of household) has been followed-up annually. This study sample focuses on the 427 young adults ( $73 \%$ of original African-American cohort) who provided any data on their gambling and sexual histories up to age 18. Chi-square tests showed no differences by sex, race, percentage receiving subsidized lunches, household structures, or intervention condition between the current sample and the original full cohort ( $\mathrm{p}$-values $>.05$ ).

Data were collected via a self-administered, 60-90-minute computer interview, or for those located out of the geographic region, via telephone. Study protocols were approved by the Johns Hopkins University Institutional Review Board.

Measures

Gambling Behavior-The South Oaks Gambling Screen-Revised for Adolescents (SOGS-RA) (K. Winters, Stinchfield, \& Fulkerson, 1993) assesses annual gambling frequency, activities, and problems using 12 items whose wordings and response options reflect adolescent gambling behavior at an age appropriate reading level. Participants were classified as either nongamblers or gamblers based on their involvement in gambling activities (e.g., slots, lottery, betting). Information about how frequently participants gambled further classified gamblers as those who gamble infrequently (i.e., less than once a week) or those who gamble frequently (i.e., more than once a week) (Stinchfield, 2000; Storr, Lee, Derevensky, Ialongo, \& Martins, 2012). The 12 gambling-related problem items (e.g., hiding evidence of gambling, spending more time or money gambling than intended) were used to distinguish gamblers with at least one gambling problem from those with no gambling problems (Storr et al., 2012; Welte, Barnes, Tidwell, \& Hoffman, 2009). The current study used the SOGS-RA data which reflects gambling behaviors at ages 16 and 18 to create cumulative measures of the gambling variables (i.e., ever gambling, gambling frequency, any gambling problems) using participant's highest involvement at any year.

Adolescent Sexual History-Lifetime history of sexual behavior up to age 18 was collected via computer -assisted self-reports during the age 19 assessment. Participants first 
identified the specific types of sexual activities they had engaged in during their lifetime (i.e., vaginal, oral, anal intercourse) and whether they were sexually active in the 6 months prior to the interview. Follow-up items assessed age of onset for each type of sexual intercourse. For the small portion of the sample with missing data on the age of onset (1.2\%), their age at the time of the interview (i.e., 18 or 19 years old) was used instead. Lifetime vaginal, oral, and anal sexual activities were aggregated into one variable to indicate whether each participant had ever engaged in any sexual intercourse activity. Age 13 was used as the cut-off to identify early versus later sexual initiation, similar to cut-offs from other studies (Coker et al., 1994; Stanton et al., 2001). Data on any lifetime sexually transmitted infections (STI; i.e., HIV/AIDS, syphilis, gonorrhea, genital herpes, and genital warts), any lifetime condom use during sex, any lifetime pregnancy or impregnation, types of sexual partners (i.e., main partner, acquaintance, friend, onetime partner, unknown partner) in the past month, and number of sexual partners in the past month were also collected via self-report. Participants with at least two sex partners in the past month and/or at least two types of partners were categorized as those with multiple recent partners.

\section{Covariates}

Eighth-grade (age 13) impulsivity: Impulsivity was assessed in grade eight (age 13) via a subscale in the Teacher Observation of Classroom Adaptation-Revised (Werthamer-Larsson, Kellam, \& Wheeler, 1991). Teachers rated each youth as 1 (never) to 6 (always) on the following items: interrupts or intrudes on others and blurts out answer before question is complete. A third additional item (waits for turn) was reverse-coded as $1=$ always to $6=$ never. The Cronbach's alpha coefficient for reliability was 0.79 . For each participant, the sum of the three items was first averaged then dichotomized to distinguish participants with scores at or above the $75^{\text {th }}$ percentile and those with scores below the $75^{\text {th }}$ percentile to represent eighth-grade impulsivity. Previous research on the TOCA-R has demonstrated a high level of predictive validity (Petras, Masyn, \& Ialongo, 2011).

Substance use: Past year use of alcohol and illegal drugs (i.e. marijuana, crack, cocaine, heroin, inhalants and ecstasy) were assessed annually from ages 12-18 through answers collected from the Monitoring the Future National Survey (Johnston, O’Malley, \& Bachman, 1998) and the National Survey on Drug Use and Health (Substance Abuse and Mental Health Services Administration, 2005). Based on these variables we created two dichotomous variables that distinguished participants who reported alcohol use by age 18 and illegal drug use by age 18 .

Eighth grade (age 13) anxiety and depressive symptoms: The Baltimore How I FeelAdolescent Version (BHIF-AY), a 45-item self-report scale, assessed depressive and anxious symptoms in adolescence (N. S. Ialongo et al., 1999). Adolescents reported the frequency of symptoms over the last two weeks using a Likert rating $(1=$ never; $4=$ always or almost always). Separate depressive and anxious summary scores were created for each individual by first summing the 19 depressive-related items and the 26 anxious-related items and then dividing each by the number of items. The two summary scores were next separately dichotomized to distinguish participants with scores at or above the $75^{\text {th }}$ 
percentile from those with scores below the $75^{\text {th }}$ percentile. In the present sample, alpha was .82 for the Depression subscale and .82 for the Anxiety subscale.

Demographic characteristics: Race, gender, household structure (i.e., two-parent/ caregiver, single-parent/caregiver), lunch status (i.e., full priced, subsidize priced), and intervention status were collected at baseline when the sample was age 6 .

\section{Analysis}

Following initial exploratory analysis (e.g., Chi-square tests), we conducted a series of multivariable logistic regression models. These models yielded odds ratio estimates (95\% confidence intervals and p-values) that quantified the strength of the association between the gambling behaviors (i.e., ever gambling, gambling frequency, and any gambling problems) and the various sexual behaviors and sequelae. Covariates in these models included race, gender, household structure, lunch status, family structure, intervention status, eighth grade (age 13) impulsivity, and depressive and anxiety symptoms. A priori interaction effects between the various sexual behaviors and both age 13 impulsivity level and gender on gambling outcomes were separately tested on the multiplicative scale. To accommodate the initial sample design (clustering of students within schools), a variant of the Huber-White sandwich estimator of variance to obtain robust standard errors and variance estimates was used (Rogers, 1994). All analyses were performed using STATA 11.0 (StataCorp, 2009). Associations were considered statistically significant if p-values were lower than 0.05.

\section{Results}

Almost half of the sample $(49 \%, \mathrm{n}=211)$ had gambled at least once by age 18 .

Approximately one third (35\%) had initiated sexual intercourse by age 13 and nearly all had engaged in sexual intercourse by age 18 (89\%), but only a third (34\%) of those who had sex by 18 were sexually active in the six months prior to being interviewed $(n=129)$. Nine percent of the sexually active youth $(n=35)$ ever had an STI.

Compared to non-gamblers, there was a trend for gamblers to be significantly more likely to have engaged in sexual intercourse by age 13 (43\% vs. 28\%, aOR: 1.46 [0.91-2.34], see Tables 1 and 2), and they were significantly more likely than non-gamblers to have engaged in sexual intercourse by age 18 (93\%, vs. 84\%, aOR: 2.29 [1.16-4.52]), adjusted for all covariates. Among sexually active youth $(\mathrm{N}=378)$, there was no association between gambling and having a STI, unprotected sex, having multiple sex partners in the past month or becoming pregnant/ impregnating someone (Tables 1 and 2).

Among those who had gambled by age $18,46 \%(\mathrm{n}=100)$ were frequent gamblers. Unadjusted models show that frequent gamblers were 1.6 times more likely than infrequent gamblers to have initiated sex by age 13 (52\% vs. $41 \%$; OR: 1.63 [1.08-3.47]), but this became non-significant upon adjustment for the various covariates (aOR: 1.27[0.75-2.15], Table 2). There were no other differences in sexual behavior between frequent and infrequent gamblers. Fifty-six percent $(n=121)$ of the gamblers had experienced any gambling problems by age 18 . Similar to before, while the unadjusted association was significant between gambling problems and sex by age 13 (69\% vs. 55\%, OR: 1.79 [1.07- 
2.99]), such association were attenuated upon covariate adjustment and became nonsignificant (Table 2). No other differences were found in sexual behaviors between gamblers with and without gambling problems.

Table 3 shows the association between sexual behavior and gambling/ gambling status by age 13 impulsivity levels. For gambling vs. non-gambling, only the interaction between impulsivity and pregnancy/impregnation was found to be significant. More specifically, among those who had initiated sexual activity by age 18, the adjusted association between gambling and pregnancy/impregnation among participants with impulsivity scores at or above the $75^{\text {th }}$ percentile (aOR: $7.71[1.58-37.66]$ ) and those with scores below the $75^{\text {th }}$ percentile (aOR: 0.76 [0.34-1.73]) was statistically significantly different. While the relationships between frequent gambling and both lifetime STI and pregnancy/impregnation among gamblers who initiated sex by age 18 were significant among those below the impulsivity $75^{\text {th }}$ percentile but not significant among those at or above the $75^{\text {th }}$ percentile, such associations did not differ significantly between the two impulsivity levels.

Table 4 shows the association between sexual behavior and gambling/gambling status by gender. As with the impulsivity interaction analyses presented in Table 3, only the interaction between gender and pregnancy/impregnation for ever gambling among those who had initiated sexual activity was found to be significant, as the adjusted associations between gambling and pregnancy/impregnation among women (OR: 1.33 [0.72-2.45]) and men (OR: 4.95 [1.25-19.60]) differed significantly.

\section{Discussion}

The main findings of this manuscript can be summarized as follows: among a sample of African-American youth a) more gamblers than non-gamblers had initiated sexual intercourse by age 18; b) among those who had initiated sexual activity, more gamblers than non-gamblers with high impulsivity levels at age 13 (vs. low impulsivity levels) had become pregnant or impregnated someone; c) among those who had initiated sexual activity by age 18 , more male gamblers had impregnated someone by age 18 as compared to female gamblers becoming pregnant.

This study's findings are complementary to the previous studies that have described that gambling is associated with an earlier age of onset of sexual activities in mainly Caucasian middle and high-school students (Proimos et al., 1998). However, this study goes above and beyond this prior study as it also describes significant associations between gambling and becoming pregnant or impregnating someone by age 18 among sexually active adolescents with high levels of early adolescent impulsivity. In addition, it shows that more male gamblers had impregnated someone by age 18 as compared to female gamblers becoming pregnant. Such findings show that gambling youth are not only at risk of gambling problems, which are associated with numerous adverse interpersonal, financial, criminal, and psychiatric consequences (Bellringer et al., 2009; Kessler et al., 2008; Korman et al., 2008; Williams, Royston, \& Hagen, 2005), but also at risk for sex-related sequelae such as adolescent pregnancy/impregnation. Moreover, a prior paper based upon data from this 
sample has shown that adolescent males who gambled were more likely than their nongambling peers to become fathers by the age of 20 (Lee et al., 2013).

Due to the rampant gambling opportunities youth are exposed to on a regular basis, gambling is generally a socially condoned behavior with low perceived risks among youth (Spurrier \& Blaszczynski, 2013; White, Mun, Kauffman, Whelan, \& Regan, 2007). However, the current finding of the high co-occurrence of gambling and risky sexual behaviors among adolescents highlights the need for existing prevention programs targeting adolescent problem behaviors to also incorporate a gambling prevention/intervention component. Specific interventions should focus upon improving the decision-making skills of adolescents, including techniques to negotiate safer sex attitudes with potential sexual partners (i.e., using condoms) as well as decision-making skills towards engaging in gambling activities. In addition, due to the fact that there was a strong significant interaction between high levels of impulsivity and becoming pregnant or impregnating someone among gamblers and not among non-gamblers, there is the need for future studies to explore in greater detail whether high early adolescence impulsivity (or specific aspects of this construct) is the underlying predisposing factor in the association between gambling problems and sexual risky behavior (Petry, 2000). Such studies and program development are particularly crucial among minority youth as this population is at a disproportionately higher risk of gambling problems and engagement in unprotected sex with multiple recent partners (Barry et al., 2011; Petry \& Tawfik, 2001) that could place individuals at further risk of other adverse outcomes such as substance use disorders and adolescent pregnancies (Huang et al., 2007; Kotchick et al., 2001; Petry, 2000).

It is necessary to note strengths and potential limitations of this study. This sample was comprised of African-American students from urban neighborhoods selected to be representative of all students starting first grade in the public school system in 1993. Thus, cohort effects are minimal and there is very little variation in age since they all began primary school in the same calendar year. However, the characteristics of the sample hamper generalization to other students growing up in other metropolitan areas with different racial/ cultural compositions. In addition, the observed significant association between sexual intercourse by age 18 and gambling behavior by age 18 does not necessarily indicate a causal relationship. This study's early adolescent measure of impulsivity was based upon a teacher's report of only three items. More refined impulsivity scales might be needed to tap into the underlying vulnerability that might link adolescent gambling and sexual activities. Future studies should further investigate the interaction between childhood impulsivity and adolescent sexual behavior. Last, self-reports of gambling problems and sexual behavior may be subject to reporting bias.

\section{Conclusion}

This study described associations between gambling and sexual behaviors by age 18, and found gambling to be positively associated with having engaged in sexual intercourse by age 18. Among those who had initiated sexual activity, more gamblers than non-gamblers with high impulsivity levels at age 13 (vs. low impulsivity levels) had become pregnant or impregnated someone. The findings from the present study - that youth gambling is 
associated with sexual risk-taking and attendant outcomes such as pregnancy/impregnation among gamblers who are highly impulsive, parallels findings from the adolescent substance abuse field where it has been demonstrated that relative to their non-substance using peers, youth who use substances engage in sexual intercourse at an earlier age and have higher rates of unprotected intercourse and more sexual partners, resulting in elevated pregnancy/ impregnation rates (Cavazos-Rehg et al., 2011; Cook et al., 2006; Staras, Tobler, Maldonado-Molina, \& Cook, 2011; Tapert, Aarons, Sedlar, \& Brown, 2001). Consequently, experts have argued for comprehensive interventions that target both adolescent substance use and sexual risk behaviors (Bell et al., 2003; Houck et al., 2006; Marvel, Rowe, ColonPerez, DiClemente, \& Liddle, 2009), and some progress has been made that might inform interventions designed to address adolescent gambling and sexual risk behaviors. In particular, there is agreement that youth risk behaviors influence and are influenced by the systems in which youth are embedded, particularly family and peer systems (Henggeler, Schoenwald, Borduin, Rowland, \& Cunningham, 2009). Consequently, interventions targeting youth with multiple risk behaviors should address likely mediators at the levels of the individual youth (e.g., youths self-control abilities), family (e.g., maladaptive parenting practices), and peer-group (e.g., associating with delinquent peers) (Marvel et al., 2009; McCart, Sheidow, \& Letourneau, in press; Tolou-Shams et al., 2011), all of which can be accomplished within the context of family therapy. Evaluations of two distinct interventions that target substance abusing youths' self-control, parental capacity to effectively parent and peer relationships, have yielded supportive, albeit preliminary results (Letourneau, McCart, Asuzu, Mauro, \& Sheidow, in press; Marvel et al., 2009; McCart et al., in press).

As with adolescent substance use, problems with youth self-regulation, maladaptive parenting (Vachon, Vitaro, Wanner, \& Tremblay, 2004) and peers (Langhinrichsen-Rohling, Rohde, Seeley, \& Rohling, 2004) also contribute to youth problem gambling. Consequently approaches that effectively target these areas in the context of adolescent substance use and sexual risk behaviors seem to offer a logical starting place for designing or adapting programs to comprehensively address adolescent gambling and sexual risk behaviors. Such systemic, family-based programs should also address parental gambling, particularly by fathers, youth substance use, and the influence of negative peers, all of which are related to youth gambling (Nower, Derevensky, \& Gupta, 2004; Vachon et al., 2004). More generally, multisystemic family-based interventions are among the most effective methods for addressing conduct disorder and delinquency (Henggeler \& Sheidow, 2012) and as such should provide a logical starting point for any intervention that aims to address serious youth risk behaviors.

\section{Abbreviations}

$\begin{array}{ll}\text { PG } & \text { Pathological gambling } \\ \text { STI } & \text { sexually transmitted infections } \\ \text { SOGS } & \text { South Oaks Gambling Screen } \\ \text { SOGS-RA } & \text { South Oaks Gambling Screen - Revised for Adolescents }\end{array}$




\section{References}

Barnes GM, Welte JW, Hoffman JH, Tidwell MC. Gambling, alcohol, and other substance use among youth in the United States. J Stud Alcohol Drugs. 2009; 70(1):134-142. [PubMed: 19118402]

Barry DT, Stefanovics EA, Desai RA, Potenza MN. Differences in the associations between gambling problem severity and psychiatric disorders among black and white adults: findings from the National Epidemiologic Survey on Alcohol and Related Conditions. Am J Addict. 2011; 20(1):69_ 77.10.1111/j.1521-0391.2010.00098.x [PubMed: 21175923]

Bell DN, Martinez J, Botwinick G, Shaw K, Walker LE, Dodds S, Siciliano C. Case finding for HIVpositive youth: a special type of hidden population. J Adolesc Health. 2003; 33(2 Suppl):10-22. [PubMed: 12888283]

Bellringer, M.; Abbott, M.; Coombes, R.; Brown, R.; McKenna, B.; Dyall, L.; Rossen, F. Problem gambling-formative investigation of the links between gambling (including problem gambling) and crime in New Zealand. Auckland, NZ: Gambling Research Centre, Auckland University of Technology; 2009.

Cavazos-Rehg PA, Krauss MJ, Spitznagel EL, Schootman M, Cottler LB, Bierut LJ. Substance use and the risk for sexual intercourse with and without a history of teenage pregnancy among adolescent females. J Stud Alcohol Drugs. 2011; 72(2):194-198. [PubMed: 21388592]

Coker AL, Richter DL, Valois RF, McKeown RE, Garrison CZ, Vincent ML. Correlates and consequences of early initiation of sexual intercourse. J Sch Health. 1994; 64(9):372-377. [PubMed: 7877279]

Cook RL, Comer DM, Wiesenfeld HC, Chang CC, Tarter R, Lave JR, Clark DB. Alcohol and drug use and related disorders: An underrecognized health issue among adolescents and young adults attending sexually transmitted disease clinics. Sex Transm Dis. 2006; 33(9):565570.10.1097/01.olq.0000206422.40319.54 [PubMed: 16572042]

Henggeler SW, Sheidow AJ. Empirically supported family-based treatments for conduct disorder and delinquency in adolescents. J Marital Fam Ther. 2012; 38(1):30-58.10.1111/j. 1752-0606.2011.00244.x [PubMed: 22283380]

Henggeler, SW.; Schoenwald, SK.; Borduin, CM.; Rowland, MD.; Cunningham, PB. Multisystemic Treatment of Antisocial Behavior in Children and Adolescents. Guilford Press; 2009.

Houck CD, Lescano CM, Brown LK, Tolou-Shams M, Thompson J, Diclemente R, Silver BJ. "Islands of Risk": subgroups of adolescents at risk for HIV. J Pediatr Psychol. 2006; 31(6):619629.10.1093/jpepsy/jsj067 [PubMed: 16120764]

Huang JH, Jacobs DF, Derevensky JL. Sexual risk-taking behaviors, gambling, and heavy drinking among U.S. College athletes. Arch Sex Behav. 2010; 39(3):706-713.10.1007/s10508-009-9521-7 [PubMed: 19629670]

Huang JH, Jacobs DF, Derevensky JL, Gupta R, Paskus TS. Gambling and health risk behaviors among U.S. college student-athletes: findings from a national study. J Adolesc Health. 2007; 40(5):390-397.10.1016/j.jadohealth.2006.11.146 [PubMed: 17448395]

Ialongo N, Poduska JM, Werthamer L, Kellam S. The distal impact of two first grade preventive interventions on conduct problems and disorder in early adolescence. Journal of Emotional and Behavioral Disorders. 2001; 9(146)

Ialongo NS, Werthamer L, Kellam SG, Brown CH, Wang S, Lin Y. Proximal impact of two first-grade preventive interventions on the early risk behaviors for later substance abuse, depression, and antisocial behavior. Am J Community Psychol. 1999; 27(5):599-641. [PubMed: 10676542]

Johnston, L.; O’Malley, PM.; Bachman, JG. U. D. o. H. a. H. S. National Institute on Drug Abuse. National survey results on drug use from the Monitoring the Future Study, 1975-1997. Public Health Service, National Institutes of Health; 1998.

Kessler RC, Hwang I, LaBrie R, Petukhova M, Sampson NA, Winters KC, Shaffer HJ. DSM-IV pathological gambling in the National Comorbidity Survey Replication. Psychol Med. 2008; 38(9):1351-1360.10.1017/s0033291708002900 [PubMed: 18257941]

Korman LM, Collins J, Dutton D, Dhayananthan B, Littman-Sharp N, Skinner W. Problem gambling and intimate partner violence. J Gambl Stud. 2008; 24(1):13-23.10.1007/s10899-007-9077-1 [PubMed: 17901931] 
Kotchick BA, Shaffer A, Forehand R, Miller KS. Adolescent sexual risk behavior: a multi-system perspective. Clin Psychol Rev. 2001; 21(4):493-519. [PubMed: 11413865]

Langhinrichsen-Rohling J, Rohde P, Seeley JR, Rohling ML. Individual, family, and peer correlates of adolescent gambling. J Gambl Stud. 2004; 20(1):23-46.10.1023/b:jogs.0000016702.69068.53 [PubMed: 14973396]

Lee GP, Storr CL, Ialongo NS, Martins SS. Compounded effect of early adolescence depressive symptoms and impulsivity on late adolescence gambling: a longitudinal study. J Adolesc Health. 2011; 48(2):164-169.10.1016/j.jadohealth.2010.06.002 [PubMed: 21257115]

Lee GP, Storr CL, Ialongo NS, Martins SS. Does adolescent gambling co-occur with young fatherhood? Am J Addict. 2013; 22(4):417-424.10.1111/j.1521-0391.2013.12026.x [PubMed: 23795883]

Letourneau EJ, McCart MR, Asuzu K, Mauro PM, Sheidow AJ. Caregiver involvement in sexual risk reduction with substance using juvenile delinquents: Overview and preliminary outcomes of a randomized trial. Adolescent Psychiatry. in press.

Liu W, Lee GP, Goldweber A, Petras H, Storr CL, Ialongo NS, Martins SS. Impulsivity trajectories and gambling in adolescence among urban male youth. Addiction. 2013; 108(4):780-788.10.1111/ add.12049 [PubMed: 23130867]

Marvel F, Rowe CL, Colon-Perez L, DiClemente RJ, Liddle HA. Multidimensional family therapy HIV/STD risk-reduction intervention: an integrative family-based model for drug-involved juvenile offenders. Fam Process. 2009; 48(1):69-84. [PubMed: 19378646]

McCart MR, Sheidow AJ, Letourneau EJ. Risk Reduction Therapy for Adolescents (RRTA): Targeting substance use and HIV/STI-risk behaviors. Cognitive and Behavioral Practice. in press.

National Research Council. Pathological Gambling:A Critical Review. The National Academies Press; 1999.

Nower L, Derevensky JL, Gupta R. The relationship of impulsivity, sensation seeking, coping, and substance use in youth gamblers. Psychol Addict Behav. 2004; 18(1):49-55.10.1037/0893-164x. 18.1.49 [PubMed: 15008685]

Ompad DC, Strathdee SA, Celentano DD, Latkin C, Poduska JM, Kellam SG, Ialongo NS. Predictors of early initiation of vaginal and oral sex among urban young adults in Baltimore, Maryland. Arch Sex Behav. 2006; 35(1):53-65.10.1007/s10508-006-8994-x [PubMed: 16502153]

Petras H, Masyn K, Ialongo N. The developmental impact of two first grade preventive interventions on aggressive/disruptive behavior in childhood and adolescence: an application of latent transition growth mixture modeling. Prev Sci. 2011; 12(3):300-313.10.1007/s11121-011-0216-7 [PubMed: 21519860]

Petry NM. Gambling problems in substance abusers are associated with increased sexual risk behaviors. Addiction. 2000; 95(7):1089-1100. [PubMed: 10962773]

Petry NM, Tawfik Z. Comparison of problem-gambling and non-problem-gambling youths seeking treatment for marijuana abuse. J Am Acad Child Adolesc Psychiatry. 2001; 40(11):13241331.10.1097/00004583-200111000-00013 [PubMed: 11699807]

Proimos J, DuRant RH, Pierce JD, Goodman E. Gambling and other risk behaviors among 8th- to 12th-grade students. Pediatrics. 1998; 102(2):e23. [PubMed: 9685469]

Rogers W. Regression standard errors in clustered samples. Stata Technical Bulletin. 1994; 13:19-23.

Spurrier M, Blaszczynski A. Risk Perception in Gambling: A Systematic Review. J Gambl Stud. 201310.1007/s10899-013-9371-z

Stanton B, Li X, Cottrell L, Kaljee L. Early initiation of sex, drug-related risk behaviors, and sensation-seeking among urban, low-income African-American adolescents. J Natl Med Assoc. 2001; 93(4):129-138. [PubMed: 12653400]

Staras SA, Tobler AL, Maldonado-Molina MM, Cook RL. Riskier sexual partners contribute to the increased rate of sexually transmitted diseases among youth with substance use disorders. Sex Transm Dis. 2011; 38(5):413-418.10.1097/OLQ.0b013e31820279a7 [PubMed: 21139514]

StataCorp. Stata Statistical Software: Release 11. College Station, TX: 2009.

Steel Z, Blaszczynski A. Impulsivity, personality disorders and pathological gambling severity. Addiction. 1998; 93(6):895-905. [PubMed: 9744125] 
Stinchfield R. Gambling and correlates of gambling among Minnesota public school students. J Gambl Stud. 2000; 16(2-3):153-173. [PubMed: 14634311]

Storr CL, Lee GP, Derevensky JL, Ialongo NS, Martins SS. Gambling and adverse life events among urban adolescents. J Gambl Stud. 2012; 28(2):325-336.10.1007/s10899-011-9254-0 [PubMed: 21614529]

Substance Abuse and Mental Health Services Administration. OoA Studies. Overview of Findings from the 2004 National Survey on Drug Use and Health. Rockville, MD: 2005. NSDUH Series H-27, DHHS Publication No. SMA 05-4061

Tapert SF, Aarons GA, Sedlar GR, Brown SA. Adolescent substance use and sexual risk-taking behavior. J Adolesc Health. 2001; 28(3):181-189. [PubMed: 11226840]

Tolou-Shams M, Houck C, Conrad SM, Tarantino N, Stein LA, Brown LK. HIV prevention for juvenile drug court offenders: a randomized controlled trial focusing on affect management. $\mathrm{J}$ Correct Health Care. 2011; 17(3):226-232.10.1177/1078345811401357 [PubMed: 21474529]

Vachon J, Vitaro F, Wanner B, Tremblay RE. Adolescent gambling: relationships with parent gambling and parenting practices. Psychol Addict Behav. 2004; 18(4):398401.10.1037/0893-164x.18.4.398 [PubMed: 15631615]

Welte JW, Barnes GM, Tidwell MC, Hoffman JH. Association between problem gambling and conduct disorder in a national survey of adolescents and young adults in the United States. $\mathrm{J}$ Adolesc Health. 2009; 45(4):396-401.10.1016/j.jadohealth.2009.02.002 [PubMed: 19766945]

Welte JW, Barnes GM, Wieczorek WF, Tidwell MC, Parker JC. Risk factors for pathological gambling. Addict Behav. 2004; 29(2):323-335. [PubMed: 14732420]

Werthamer-Larsson L, Kellam S, Wheeler L. Effect of first-grade classroom environment on shy behavior, aggressive behavior, and concentration problems. Am J Community Psychol. 1991; 19(4):585-602. [PubMed: 1755437]

White, MA.; Mun, P.; Kauffman, N.; Whelan, C.; Regan, M. Teen gambling in Ontario: Behaviors and perceptions among 15-to-17-year-olds. Toronto, ON: Responsible Gambling Council; 2007.

Williams RJ, Royston J, Hagen BF. Gambling and problem gambling within forensic populations: a review of the literature. Criminal Justice and Behavior. 2005; 32:665-689.

Winters KC, Stinchfield RD, Botzet A, Anderson N. A prospective study of youth gambling behaviors. Psychol Addict Behav. 2002; 16(1):3-9. [PubMed: 11934084]

Winters KC, Stinchfield RD, Fulkerson J. Toward the development of an adolescent gambling problem severity scale. Journal of Gambling Studies. 1993; 9(1):63-84.10.1007/BF01019925

Zuckerman M, Kuhlman DM. Personality and risk-taking: common biosocial factors. J Pers. 2000; 68(6):999-1029. [PubMed: 11130742] 


\section{Highlights}

- We assessed the degree to which adolescent sexual behaviors and gambling were associated.

- Data are derived from a cohort study with large African-American presence.

- Almost half of the sample $(49 \%, \mathrm{n}=211)$ had gambled at least once before age 18. More gamblers than non-gamblers had initiated sexual intercourse by age 18 (aOR: 2.29[1.16, 4.52]).

- Among those who had initiated sexual activity, more gamblers than nongamblers with high impulsivity levels at age 13 (vs. low impulsivity levels) had become pregnant or impregnated someone.

- Among those who had initiated sexual activity by age 18 , more male gamblers had impregnated someone by age 18 as compared to female gamblers becoming pregnant. 


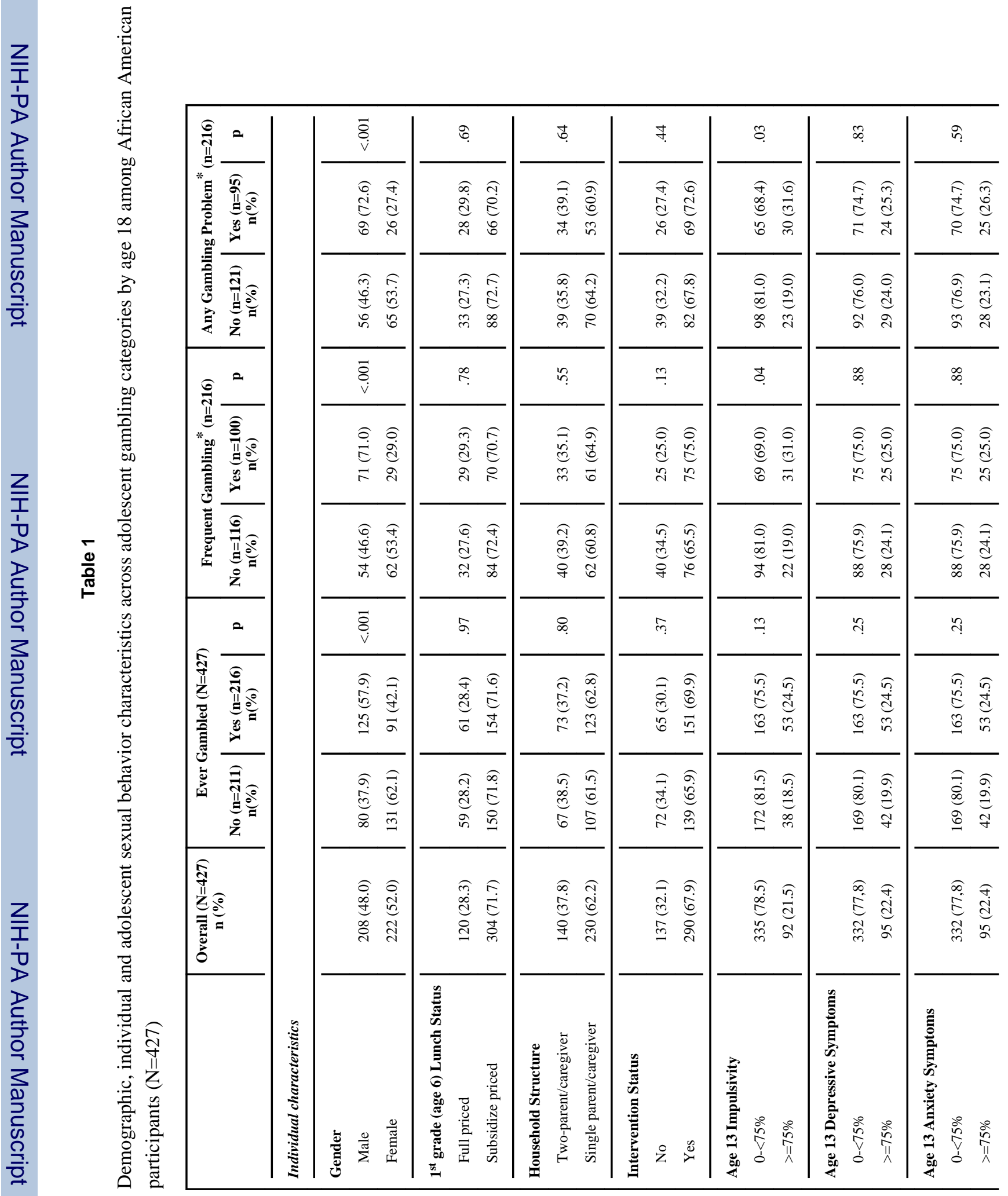




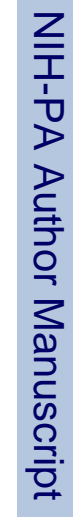

\begin{tabular}{|c|c|c|c|c|c|c|c|c|c|c|c|}
\hline & ণิ & t. & & t. & t. & & fo & & $\exists$ & & $\stackrel{?}{?}$ \\
\hline 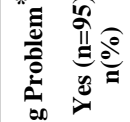 & 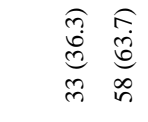 & 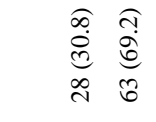 & & 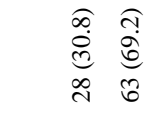 & 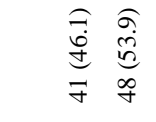 & & 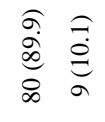 & & 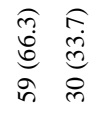 & & 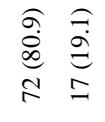 \\
\hline 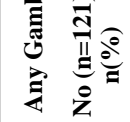 & 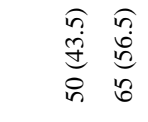 & 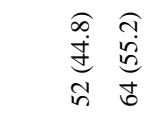 & & 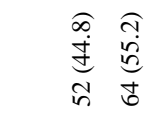 & 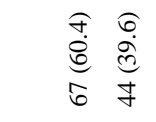 & & 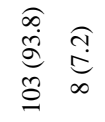 & & 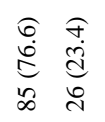 & & 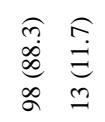 \\
\hline & $\exists$ & 8 & & $?$ & $\bar{\oplus}$ & & ते & & $\fallingdotseq$ & & 8 \\
\hline 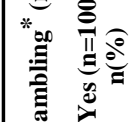 & 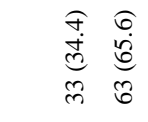 & 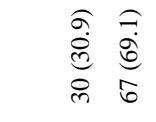 & & 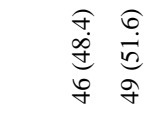 & 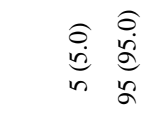 & & 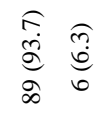 & & 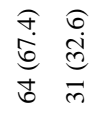 & & 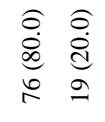 \\
\hline 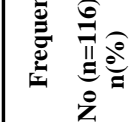 & 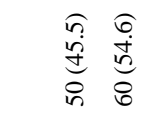 & 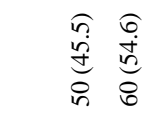 & & 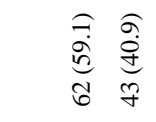 & 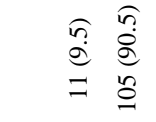 & & 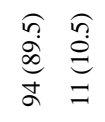 & & 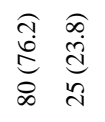 & & 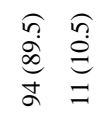 \\
\hline$\approx$ & 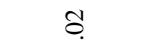 & $\bar{a}$ & & $\bar{\varepsilon}$ & $\bar{a}$ & & के & & 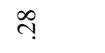 & 跣 & $\stackrel{\infty}{\hookrightarrow}$ \\
\hline 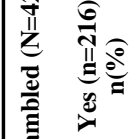 & 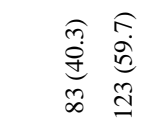 & 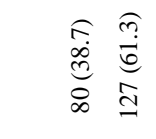 & & 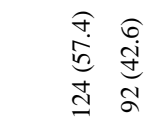 & 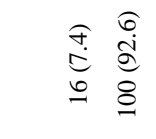 & & 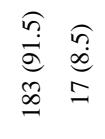 & 胥 & 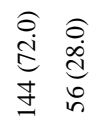 & 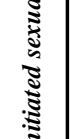 & 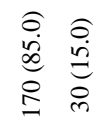 \\
\hline 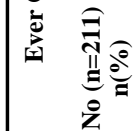 & 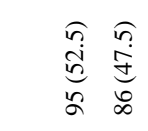 & 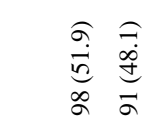 & & 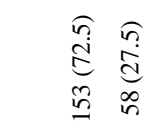 & 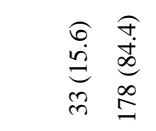 & 胥 & 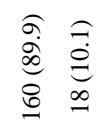 & 苞 & 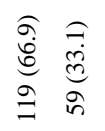 & 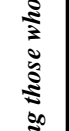 & 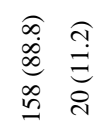 \\
\hline 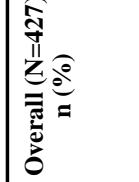 & 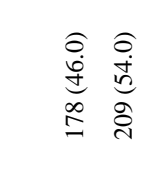 & 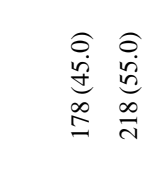 & & 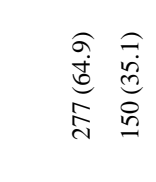 & 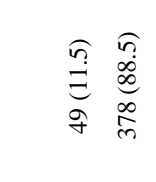 & 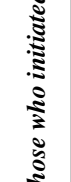 & 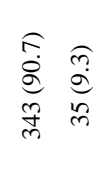 & 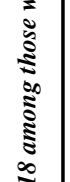 & 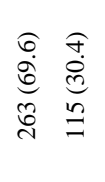 & 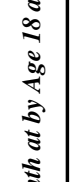 & 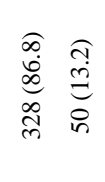 \\
\hline & 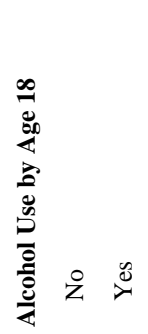 & 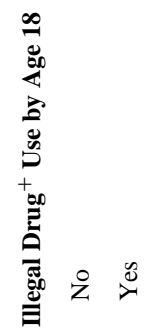 & 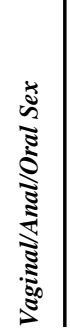 & 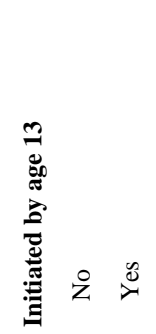 & 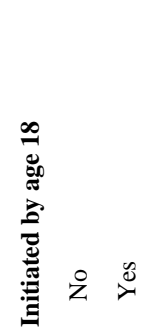 & 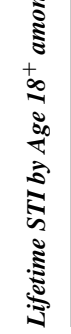 & $\ddot{z}: 0$ & 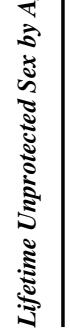 & $\ddot{z}: 0$ & 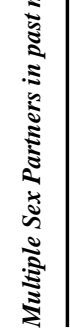 & 里 \\
\hline
\end{tabular}




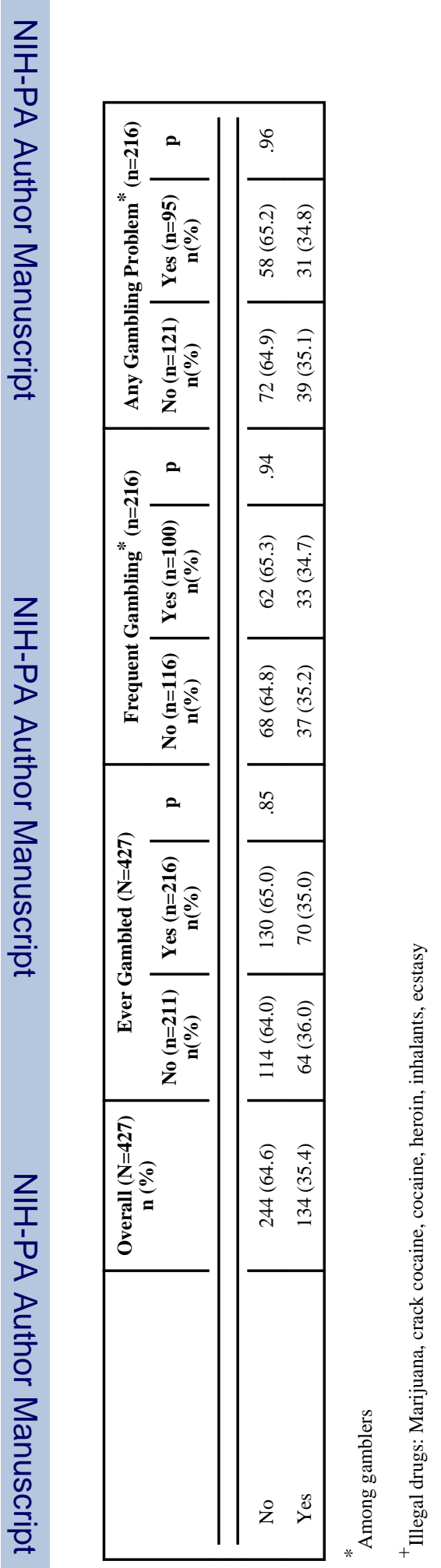




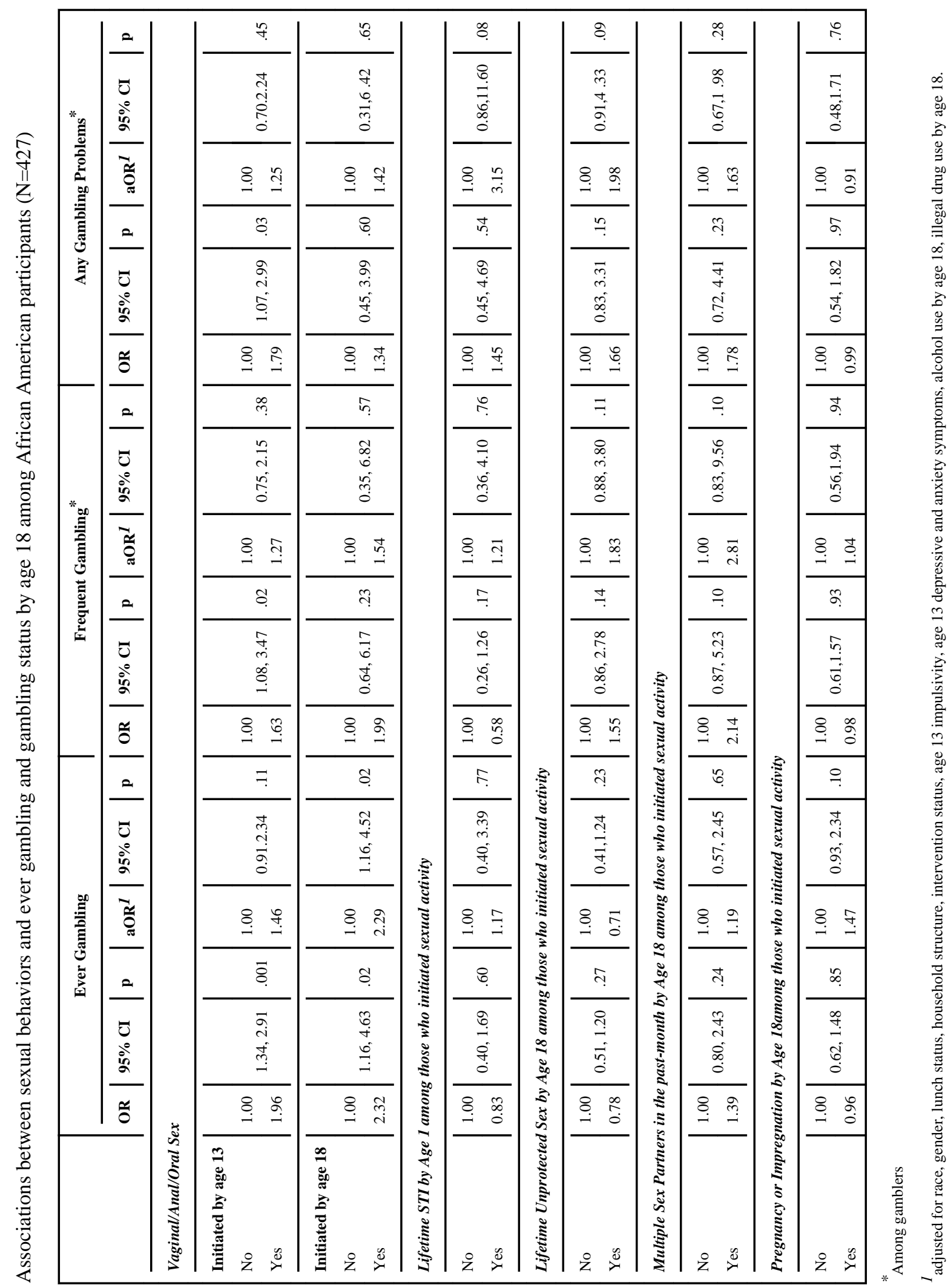




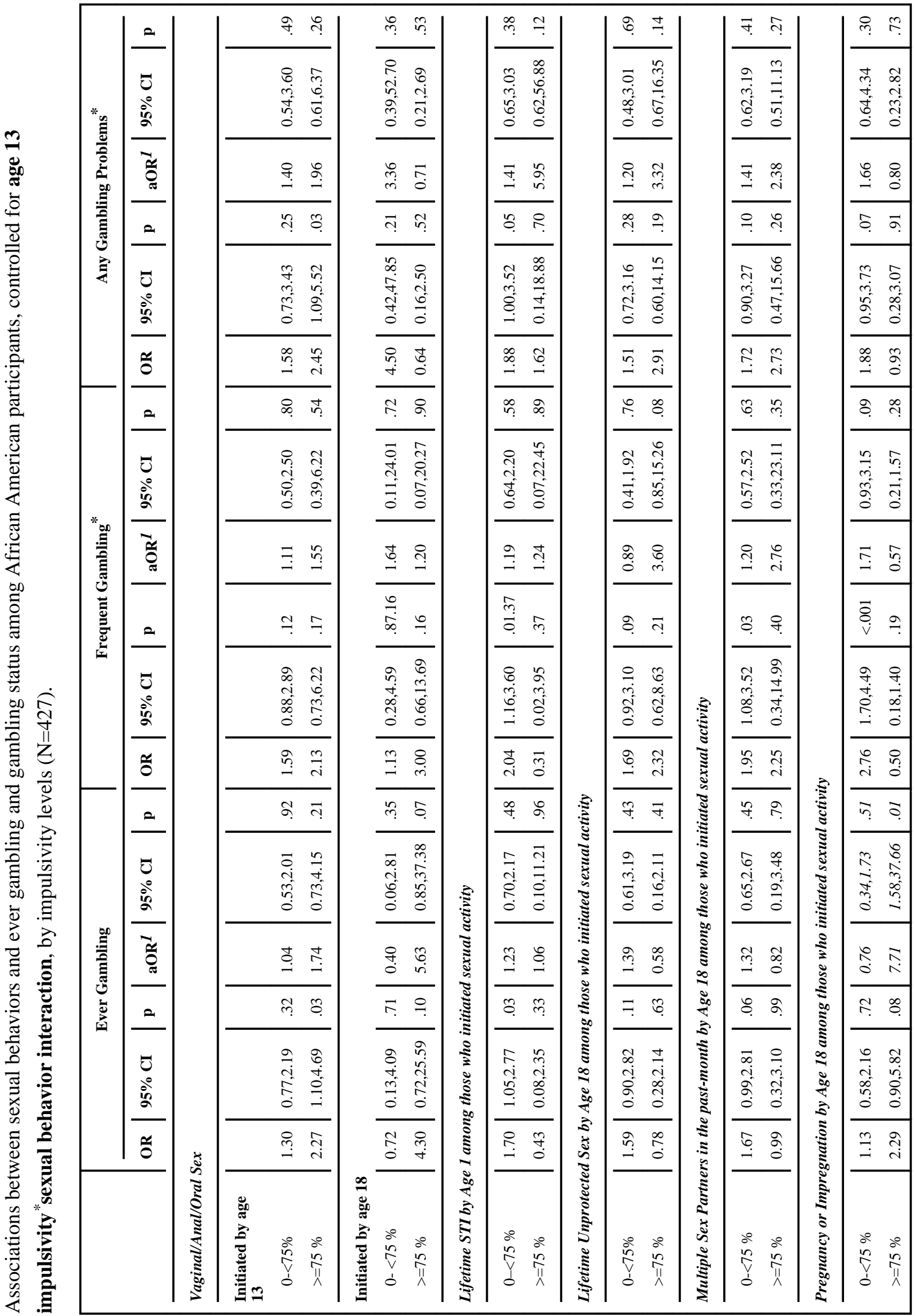




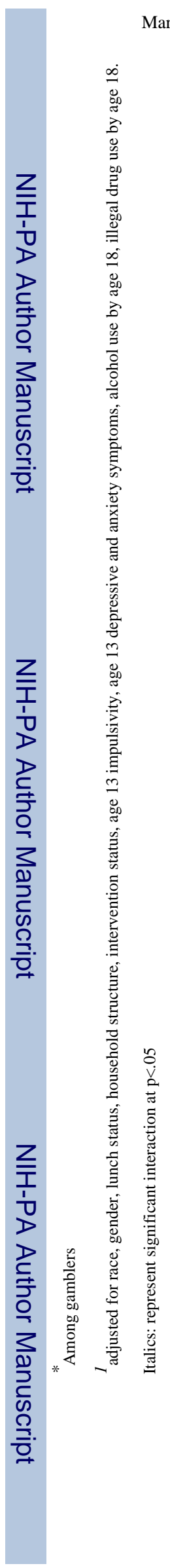

Martins et al.

Page 18 


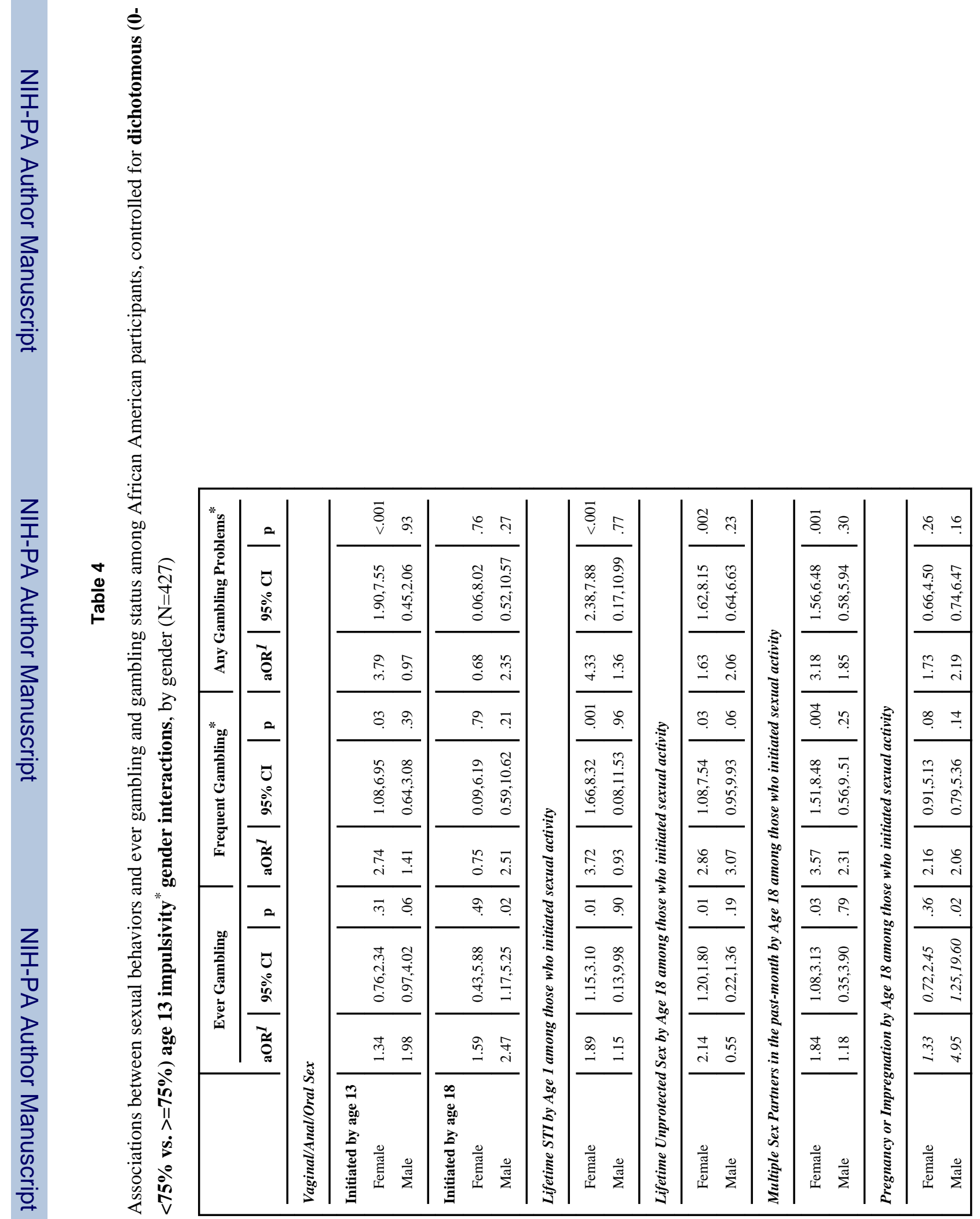

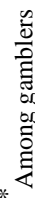


